BSN 2206-324

\title{
TEATRALIDADE E PERFORMATIVIDADE: ESPAÇOS EM DEVIR, ESPAÇOS DO DEVIR
}

Patricia Leonardelli

Pós-doutoranda no grupo LUME- Núcleo Interdisciplinar de Pesquisas Teatrais da Unicamp. Doutora em Artes pela Universidade de São Paulo. 
RESUMO: O artigo propõe uma leitura dos conceitos de teatralidade e performatividade propostos pela teórica Josette Féral à luz da filosofia pósestruturalista aplicada às Artes do Corpo. Desejamos aproximar as duas famílias teóricas para confrontar os termos de trabalho, centrais no pensamento das Artes da Cena contemporânea, e abrir a perspectiva de campo de criação para além dos materiais imediatos de trabalho.

PALAVRAS-CHAVE: Performatividade; Teatralidade; Devir; Espaço; Criação.

\begin{abstract}
The article proposes a reading of the concepts of theatricality and performativity proposed by Josette Feral in the light of poststructuralist philosophy applied to the Body Arts. We wish to bring the two families to confront the theoretical terms of work, central to the thinking of contemporary Arts Scene, and open the prospect of creating field beyond the immediate work materials.
\end{abstract}

KEYWORDS: Performativity; Theatricality; Incoming; Space; Creation.

Teatralidade, performatividade e teatro performativo, tanto quanto teatro pósmoderno e teatro pós-dramático são conceitos que vêm afirmando sua potência epistemológica no dinâmico quadro referencial das artes contemporâneas. Sua eficiência ultrapassa o âmbito das artes da cena (artes do corpo, artes cênicas, disciplina que parece cada vez mais buscar na vizinhança com o termo (arte) performativ(a)idade suas possíveis e necessárias delimitações), servindo como ferramenta teórica de conceituação para a literatura, o cinema, e outras áreas sobre as quais não estenderemos nossa reflexão. A terminologia proposta por Josette Féral constitui, em si, um modelo autônomo de análise dos fenômenos teatrais de nossa época, e partiremos desse modelo para iniciarmos um diálogo com as matrizes teórico-filosóficas que adotamos em nosso projeto sobre os temas específicos de estudo, qual sejam: a memória, a percepção e as micropercepções.

Para o desenvolvimento do debate, é conveniente, antes, levantarmos precisamente parte da problemática que envolve a definição de teatralidade, performatividade e teatro performativo como estabelecida pela autora, não para apresentar exegeses desnecessárias, mas no sentido de esclarecer minimamente a trajetória que permitiu a formação dos conceitos-chave com os quais iremos nos 
confrontar. Trajetória que tem início na tensão gerada entre as duas principais orientações de estudo do Teatro desenvolvidas no fim do século passado: a linha dos Estudos Performativos, que relaciona os processos performáticos para além das fronteiras ontológicas, tradicionalmente específicas da arte teatral, buscando suas implicações no campo da Antropologia e dos fenômenos interculturais; e a abordagem que parte do estatuto original da arte da performance como configurado desde as vanguardas históricas até o início dos anos 80.

Féral identifica, no cruzamento das duas perspectivas, a filiação de grande parte do horizonte de criação cênica contemporânea. Os Estudos Performativos, ou a Teoria da Performance, como concebidos por Richard Schechner desde The End of Humanism (1982), expandem o campo de identificação da performance a inúmeros domínios além das artes. Partindo do princípio de que a performance acontece, fundamentalmente mediante três operações (1. A criação de um comportamento que gera uma ação; 2. A efetivação da ação; 3. A apresentação de tal ação), diversos acontecimentos culturais, desde atividades esportivas, até rituais e mesmo produtos midiáticos, comportariam um caráter performativo que, de fato, seria intrínseco à condição humana, variando apenas conforme o conjunto de convenções que determinam sua expressão.

Essa abordagem, embora conduza o conceito a um esgarçamento tal que pode torná-lo epistemologicamente frágil, permite conceber a performatividade como um processo que não se desencadeia estritamente mediante os recursos materiais e humanos específicos do Teatro, nem está limitado a quaisquer operações arbitrárias da linguagem teatral. Mais do que isso, abre caminho para se entender a performance como um evento que radicalmente não está a priori apenas nos objetos e nem somente nos participantes envolvidos, sugerindo uma metafísica do ato performativo que sustentará tanto a noção de teatralidade como de performatividade desenvolvidas pela pesquisadora.

Por outro lado, foi graças à construção de um corpo técnico-conceitual a respeito da arte da performance strictu sensu que a teoria teatral pôde reconhecer 
os conteúdos disciplinares a partir dos quais é possível confrontar a moderna teoria do teatro dramático e, por cujo embate, avançar no esforço de sugerir possíveis definições para a heterogênea produção da cena contemporânea. Pela confluência paradoxal entre o reconhecimento do estatuto da performance como linguagem, de seus conteúdos, e uma perspectiva teórica que compreende o fenômeno performativo para além dos materiais que, precisamente, caracterizariam tal linguagem é que se definem nossos três conceitos abordados.

Iniciemos por aquele historicamente mais antigo, e, talvez, cuja apropriação venha se dando de forma mais confusa por crítica e criadores, a teatralidade. A despeito de muito se caracterizar determinados espetáculos como cheios ou não "de teatralidade" (funcionando tanto como comentário positivo, quanto negativo, dependendo da situação), a teatralidade como apresentada por Ferál ${ }^{1}$ não remete aos elementos e convenções tipicamente associados ao Teatro e ao fazer teatral. De fato, é exatamente o oposto. Observemos a citação:

Todavia, nós podemos extrair uma importante conclusão disto: teatralidade tem pouco a ver com a natureza do objeto investido o ator, o espaço, objeto ou evento - nem é necessariamente o resultado de uma pretensa ilusão, um faz-de-conta ou uma ficção. Se fossem estas condições pré-requisitos da teatralidade, nós não estaríamos aptos a identificar sua presença nos acontecimentos diários. Mais do que uma propriedade com características analisáveis, a teatralidade parece ser um processo que tem a ver com um 'olhar' que postula e cria um espaço virtual, distinto, que pertence ao outro, por onde a ficção pode emergir (...) o olhar do espectador cria uma ruptura espacial por onde a ilusão emerge ilusão cujo veículo o espectador selecionou de vários eventos, comportamentos, corpos físicos, objetos e espaço sem considerar a natureza real ou ficcional da origem do veículo. A Teatralidade ocorreu sob duas condições: primeiro, através de uma realocação feita pelo performer do espaço cotidiano que ele ocupa; segundo,

\footnotetext{
1“A Teatralidade não se manifesta de um modo obrigatório. Ela não tem propriedades qualitativas que nos permitem identificá-la sem sombra de dúvida. Ela não é um dado empírico". In: Theatricality: The Specifity of Theatrical Language. SubStance, Vol. 31, Edição 98/99 e Edição Especial: Teatralidade 2002, p. 98. The University of Wisconsin Press.

A respeito de nossa observação, há de se considerar, evidentemente, as diferenças no que tange à noção de teatralidade proposta pela autora e aquelas apresentadas em outros momentos históricos, especialmente por Evreinoff e Meyerhold.
} 
através de um olhar do espectador que emoldura o espaço cotidiano que ele não ocupa. Tais condições criam uma ruptura entre o espaço 'fora' e o espaço 'dentro' da teatralidade. Esse espaço é o espaço do 'outro', é o espaço que define tanto a alteridade quanto a teatralidade (FÉRAL, 1998). ${ }^{2}$ (Todas as traduções são de minha autoria).

Em relação ao termo inglês gaze, que literalmente significa um olhar fixo, arriscamos tomar também como recorte. Recorte, pois, como visto acima, a teatralidade só é possível pela ruptura (cleft), um olhar que cause ruptura no espaço cotidiano. No texto supra referido, Féral apresenta três exemplos distintos para explicar a instauração da teatralidade. No primeiro caso, um espectador entra em um teatro em que cenário e objetos de cena estão montados, mas não há atores. $A$ teatralidade se dá pela semiotização do espaço, em que a identificação dos códigos teatrais promove uma associação quase imediata do espectador com os enunciadores da cena. Observemos, porém, que os materiais por si, ainda que agentes semiotizantes denotativos da linguagem teatral, não são suficientes para determinar o grau de teatralidade. É no reconhecimento do espectador desses materiais, e na consequente construção de um espaço ficcional por parte do espectador na relação com tais elementos, que a condição se dá. Notemos, aqui, um ponto importante: para a autora, a teatralidade demanda um encontro de alteridades, não necessariamente de indivíduos (prescinde da participação de atores).

\footnotetext{
2 "Nonetheless, we can draw an important conclusion from it: theatricality has little to do with the nature of the invested object - the actor, space, object or event - nor is it necessarily the result of pretense illusion, make-believe or fiction. Were such conditions prerequisites of theatricality, we would have been unable to identify its presence in everyday occurrences. More than a property with analyzable characteristics, theatricality seems to be a process that has to do with a 'gaze' that postulates and creates a distinct, virtual space belonging to the other, from which fiction can emerge (...) the spectator' s gaze created a spatial cleft from which illusion emerge - illusion whose vehicle the spectator had selected from among events, behaviours, physical bodies, objects and space without regard for the fictional or real nature of the vehicle' $s$ origin. Theatricality occurred under two conditions: first, through a performer's reallocation of the quotidian space that he occupies; second, through a spectator' s gaze framing a quotidian space that he does not occupy. Such actions create a cleft that divides the space in the 'outside' and the 'inside' of the theatricality. This space is the space of the 'other'; it is the space that defines both alterity and theatricality."
} 
No exemplo seguinte, um espectador presencia a discussão entre duas pessoas no metrô: um fumante que não respeita as leis do transporte coletivo e um passageiro que quer que este apague o cigarro. Aqui, o espectador é atingido por uma situação de intenção teatral (o embate clássico entre protagonista e antagonista), e re-semiotiza o espaço conforme sua capacidade de efabulação. 0 estímulo para a ruptura ficcional se dá pela intenção teatral dos indivíduosperformers em semiotização altamente flutuante (os homens que discutem, performadores operando no limite entre a atuação dramática e a ação cotidiana, a personagem e a personalidade, o discurso cotidiano e aquele dramático, etc.).

E, por fim, o espectador está sentado em um café na calçada e apenas observa o vai-e-vém dos pedestres. Subitamente, algum elemento desses transeuntes desperta a consciência do espectador para a teatralidade da situação ou da figura (pode ser um gesto, um movimento, uma referência qualquer), e, mesmo que esse indivíduo observado não tenha, em si e nas suas ações, qualquer intenção ou consciência teatrais, a priori, o espectador pode inscrever a teatralidade no espaço real que ambos ocupam.

Como observamos nos três exemplos, é essa capacidade de inscrição da ficção em acontecimentos e espaços cotidianos que permite desencadear o processo da teatralidade para além do âmbito privilegiado da semiotização teatral (identificada no primeiro caso do texto), e sugere uma metafísica da teatralidade que abre um campo vigoroso de debate. ${ }^{3} 0$ processo inicia quando algum dos

\footnotetext{
3 "Vista desta forma, a teatralidade aparece com uma estrutura transcendental cujas características gerais são assumidas pelo teatro. Assim, a teatralidade ligada à cena é possível somente por causa da sua natureza transcendental. Visto por outro ângulo, o teatro é possível porque existe a teatralidade e porque o teatro a convoca. Uma vez evocada, a teatralidade emprega características especificamente teatrais que são valorizadas coletivamente e socialmente significativas. No entanto, a teatralidade da cena não poderia existir se a natureza da teatralidade não fosse transcendente."

"Seen in this way, theatricality appears as a transcendental structure whose general characteristics are assumed by the theater. Thus, stage-related theatricality is possible only because of its transcendent nature. In other word, theater is possible because theatricality exists and because the theater calls it into play. Once evoked, theatricality takes on specifically theatrical characteristics that are collectively valued and socially meaningful. However, the theatricality of the stage could not exist were the nature of theatricality not transcendent." (FÉRAL, 1998-99, p. 98-99). O teatro existe por que
} 
participantes (performador ou espectador, as funções não estão definidas aprioristicamente, podendo, inclusive, como já foi dito, que se inicie por uma relação homem-objeto), que estão no mesmo ambiente, agindo, vendo e sendo vistos, recebe um estímulo e, por caminhos não precisamente explicados pela autora, identifica um elemento de alteridade.

O encontro e reconhecimento do "outro", e, fundamentalmente, do "espaço do outro" como "outro" representa, aqui, o instante de distanciamento, de descolamento do participante daqueles domínios que ele reconhece como "reais", por serem mais próximos de suas referências do cotidiano, provocando a ruptura/“cleft" pela qual a ilusão encontra lugar para emergir. O participante entra em uma zona de significados fugidios, cujos sentidos serão construídos exatamente na medida em que se define o desenho ficcional de sua inscrição. A autora utiliza a expressão "framed theatrical space", algo como "espaço teatral enquadrado/emoldurado" para definir metafisicamente o locus em que tal operação se processa, mas que, de fato, se refere à própria capacidade de operar (emoldurar, enquadrar, recortar, desenhar; enfim, dar forma) a efabulação nas relações com o espaço, de criar e inscrever diversos desenhos ficcionais mediantes múltiplos estímulos desencadeados pelo encontro de alteridades:

Portanto, nós podemos concluir que a teatralidade consiste tanto em situar o objeto ou o outro em um 'espaço teatral emoldurado/recortado' (cena 3) quanto em transformar um simples evento em signos de tal maneira que ele se transforme em espetáculo (cena 2). Nesse ponto de nossa análise, a teatralidade parece ser, mais do que uma propriedade; de fato, nós podemos chamá-la de um processo que reconhece sujeitos em processo, ${ }^{4}$ é um processo de olhar e ser olhado. É um ato iniciado em um ou dois espaços possíveis: tanto aquele do ator quanto do espectador. Em ambos os casos, esse ato cria uma ruptura do cotidiano, que se transforma no espaço do outro, o espaço onde o outro tem lugar. Sem tal ruptura, o cotidiano permanece

antes existe a teatralidade como enquadramento da potência de efabulação humana, e não o contrário.

${ }^{4}$ Grifos meus. 
intacto, excluindo a possibilidade da teatralidade, e menos ainda do teatro em si ${ }^{5}$ (FÉRAL, p.98, 1998).

Tal processo envolve uma série de outras operações visíveis e invisíveis que qualificam o jogo de efabulação específico da teatralidade. Primeiramente, a ruptura surge como o instante imprevisível em que ocorre um tipo de afetação específica nos participantes. Não se trata de um atravessamento comum, cujas sínteses de resposta trabalham no campo das informações cotidianas e dos conteúdos proximais, mas de uma afetação transgressora, que demanda necessariamente para dar conta de sua materialidade, o trabalho de criação. Irrompe-se uma linha de fuga dentro da dinâmica de identificação do cotidiano que abre espaço para toda a reorganização das funções do indivíduo, e cuja resposta está exatamente no que Féral denomina de "framed theatrical space".

Não interessa, nem parece necessário, mapear as vias em que essa afetação sucede no sentido de tentar definir um caminho corpóreo pelo qual ela iniciaria. Não há regras, e qualquer tentativa nesse sentido nos parece um esforço inócuo para restringir a capacidade humana de ser afetado e de oferecer respostas criativas para essas afetações. Depende dos inúmeros desenhos afetivos, perceptivos, cognitivos que definem a(s) singularidade(s) do, segundo as palavras de Féral, sujeito em processo, bem como as especificidades, de certa forma, inefáveis que surgem no instante único do encontro das alteridades.

Sabemos, e é suficiente, que a re-semiotização do espaço, intrínseca à teatralidade, é um acontecimento que promove o trabalho de criação, a atividade humana que invariavelmente, e por excelência, exige a cooperação de todas as

\footnotetext{
5 "Therefore, we may conclude that theatricality consists as much in situating the object or the other in a 'framed theatrical space' (scenario 3) as it does in transforming a simple event into signs in such a way that it becomes a spectacle (scenario 2). At this stage of our analysis, theatricality appears to be more than a property; in fact, we might call it a process that recognizes subjects in process ${ }^{5}$; it is a process of looking at, or being looked at. It is an act iniciated in one or two possible spaces: either that of the actor or that of the spectator. In both cases, this act creates a cleft in the quotidian that becomes the space of the other, the space in which the other has a place. Without such a cleft, the quotidian remains intact, precluding the possibility of theatricality, much less of theater itself."
} 
outras instâncias, visíveis e invisíveis, do corpo para produção de resultados. E sabemos que, ainda que Féral se refira à instauração da teatralidade como um momento de aquisição de uma "consciência teatral" sobre o cotidiano, convém questionar se essa consciência está ligada ao senso comum de trazer à razão. Não nos parece que assim seja, pelo menos não no sentido de produzir uma síntese da consciência sobre o encontro das alteridades, uma vez que o processo, conduzido dessa maneira, seria potencialmente entrópico: reconduzira os participantes aos registros do cotidiano e ao reconhecimento das identidades, ao invés de estimular precisamente o necessário confronto de alteridades sem o qual a teatralidade não pode se estabelecer.

É no vazio das operações cotidianas, e no vácuo da sua ineficiência para conter e conceber a experiência presente que a teatralidade acontece. Podemos nos perguntar, nos dois últimos exemplos antes apresentados, com que finalidade 0 espectador cria molduras ficcionais para dimensionar suas experiências? Com que urgência e/ou intenção? Para dar conta de que? As respostas podem ser muitas, e, certamente, bastante distintas, mas, nesse ponto, a metafísica da teatralidade de Féral encontra eco com o pensamento de outros autores, inclusive de áreas mais ou menos contíguas às artes, sobre a possível origem inata da efabulação como operação fundamental humana para além da produção artística. Como sugere a própria autora:

Inicialmente, teatralidade parece ser uma operação cognitiva fantástica realizada tanto pelo observador quanto pelo observado. É um ato performativo criando um espaço virtual do outro, o espaço transicional discutido por Winnicott, o limiar (limen) discutido por Turner, ou o 'emoldurar' de Goffman. Ele ilumina uma passagem, permitindo que tanto o sujeito performativo quanto o espectador passem do 'aqui' para o 'algum outro lugar além'6 (FÉRAL, p. 98, 1998).

\footnotetext{
6 "Initially, teatricality appears to be an almost fantastic cognitive operation set in motion either by the observer or the observed. It's a performative act creating a virtual space of the other, the transitional space discussed by Winnicott, the threshold (limen) discussed by Turner, or Goffman's 'framing'. It clears a passage, allowing both the performing subject as well the spectator to pass from 'here' to 'elsewhere'." Acrescentaríamos, além dos pesquisadores relacionados pela autora, a preciosa análise da Prof. Dra. Suzy Frankl Sperb sobre o conceito, por ela formulado, de pulsão de criação,
} 
Vemos, então, a teatralidade claramente referenciada como um lugar entre, ou um não-lugar (utopia), um espaço suspenso. Um espaço que existe, mas no âmbito virtual. Observemos, então, as interlocuções necessárias.

A teatralidade de Féral é uma condição humana, um olhar, uma maneira de recolocar a si e aos outros (homens, objetos, palavras, sensações) no espaço, e de recolocar o próprio espaço de encontro noutro espaço, pela criação do espaço ficcional. A irrupção da teatralidade é um fenômeno que nasce da tentativa do criador de se apropriar desse encontro com a diferença, e de re-estabelecer o controle, com maior ou menor efetividade, das intensidades que lhe atravessam em tal momento (em última instância os limites sobre si mesmo como sujeito "essencialmente" ameaçado).

Cada desenho ficcional contém o jogo de forças vivenciais, dos participantes, experimentadas pelo encontro com a alteridade (termo que, no intuito de relacionar com nosso quadro de referência - a filosofia pós-estruturalista aplicada às artes do corpo - e ampliar sua conotação, substituiremos por diferença, no sentido, evidentemente, proposto por Derrida). São respostas que desejam criar um novo campo de atualizações em que os limites entre os participantes já não sejam mais aqueles da vida cotidiana, uma vez que os próprios atravessamentos transgressores desencadeados pelo encontro já transformaram, de tal forma, nos corpos participantes, o que se torna urgente a criação desse novo plano de atualizações para se organizar minimamente o fluxo de afetações. Por isso, cada moldura ficcional será sempre singular. Pois, em cada encontro com a diferença (o outro e seu espaço, segundo Féral) atuam uma série de forças visíveis e invisíveis cuja

desenvolvido em sua obra Ficção e Razão. S. Sperb sustenta, com argumentos profundamente consistentes, a hipótese de que a criação é uma pulsão humana tão fundamental para a estruturação interna do indivíduo quanto todas as demais já mapeadas por Freud. Mais do que um mecanismo de fuga da realidade, ela funcionaria como força de reafirmação diante das contingências enfrentadas, permitindo novas sínteses pelas quais toda organização psíquica do sujeito se beneficiaria. 
dinâmica e intensidade de afetação não podem ser definidas, senão pelo próprio encontro e por todos os movimentos daí resultantes.

Tomando o primeiro exemplo, podemos pensar que a teatralidade construída no encontro de um indivíduo com o cenário não poderá jamais ser definida pelo mesmo desenho ficcional que de outro. Por isso, ela não é um dado, nem um adjetivo, nem pode ser medida ou transformada em selo de qualificação ou desqualificação de uma obra. Porque ela não está na obra, e nem naquele que a vê. Está nesse urgente plano virtual que deseja, mas que não pode antecipar a natureza das atualizações produzidas pelo fluxo dos corpos-memória participantes. E, por tal organização, se produzem molduras ficcionais específicas, narrativas singulares, posto que ainda falamos de teatralidade, e não de performatividade.

Chegamos, portanto, a um limite em que não é possível avançar sem abordarmos o conceito seguinte. Enquanto a teatralidade filia-se diretamente à potência efabuladora humana, pois, as dinâmicas de enquadramento ficcional estão ligadas diretamente ao desejo de busca por representações e de construção de narrativas, a performatividade é um campo, de certa forma, anterior de trabalho criativo; uma vez que concerne às forças e efeitos relacionados à ação em si.

Evidentemente, existe ação no processo de teatralidade, mas a performatividade parece privilegiar o jogo com as ações em um campo autônomo em relação à construção de sentidos. Às palavras de Féral:

Se seguirmos nosso primeiro impulso, duas fortes idéias ( $\mathrm{sic}$ ) estão no centro da obra performativa: de um lado, seu caráter de descrição dos fatos. Por outro, as ações que o performer ali realiza. A performance toma lugar do real e enfoca essa mesma realidade na qual se inscreve desconstruindo-a, jogando com os códigos e as capacidades do espectador (como pode fazer Guy Cassier, Jan Lauwers, Heiner Goebbels, Marianne Weems ou a Societas Raffaelo Sanzio, de maneiras diversas). Essa desconstrução passa por um jogo com os signos que se tornam instáveis, fluidos, forçando o olhar do espectador a se adaptar incessantemente, a migrar de uma referência à outra, de um sistema de representação a outro, inscrevendo sempre a cena no lúdico e tentando por aí escapar da representação mimética. $O$ performer instala a 
ambiguidade de significações, o deslocamento de códigos, os deslizes de sentido. Trata-se, portanto, de desconstruir a realidade, os signos, os sentidos e a linguagem". ${ }^{7}$ (FÉRAL, Edusp, p. 191-210, 2008)

Eis a natureza específica da performatividade, a qual se opõe radicalmente à teatralidade: o desejo de não-construção de sentidos, um desejo, talvez, ainda mais radical de ruptura do cotidiano, que promove outras relações no encontro das singularidades. Falemos, aqui, de desejo, pois é nesse domínio que a performatividade parece ver melhor ilustrada a ordem de sua dinâmica processual. Se o espaço virtual da teatralidade comporta um plano desejoso de construção de sentidos, o espaço virtual da performatividade é mais veloz, por assim dizer. Sendo mais acelerado, suas partículas se combinam e separam em um tempo distinto daquele do reconhecimento (de ideias, discursos, narrativas, etc.). As atualizações, aqui, escapam (ou, mais provavelmente, desejam escapar) da efabulação, traem-se, negam-se numa provocação permanente aos mecanismos de identificação mimética.

O desejo, algo suicida, da performance (e, à reboque, do campo da performatividade) de expor arriscadamente suas operações de construção (os processos de criação em si), de se colocar permanentemente no limite da linguagem para, deste limite, tentar encontrar outras poéticas, projeta um plano de criação sem o qual já não nos parece mais possível pensar as artes da cena contemporânea. Se, de um lado, permanecem eficientes os modelos teóricos alinhados à tradição do teatro dramático, a descoberta da potência efabuladora da ação para além de estruturas narrativas (textuais ou físicas) pré-concebidas provocou uma ampliação do olhar sobre a potência de afetação que o encontro artístico pode proporcionar a partir da qual já não é mais possível recuar:

\footnotetext{
${ }^{7}$ Ainda no mesmo artigo, sobre as especificidades do conceito de ação performativa: "De fato, no cerne da noção de performance reside uma segunda consideração, a de que as obras performativas não são verdadeiras nem falsas. Elas simplesmente sobrevêm." p. 196.
} 
E, ainda sobre a potência de afetação da ação:

No teatro performativo, o ator é chamado a 'fazer' (doing), a estar presente, a assumir os riscos e a mostrar o fazer (showing the doing), em outras palavras, a afirmar a performatividade do processo. A atenção do espectador se coloca na execução do gesto, na criação da forma, na dissolução dos signos e em sua reconstrução permanente. Uma estética da presença se instaura (se met en place). Nesta forma artística, que dá lugar à performance no sentido antropológico, o teatro aspira a produzir evento, acontecimento, reencontrando o presente mesmo que esse caráter de descrição das ações não possa ser atingido. ${ }^{8}$ (FÉRAL, p. 210, 2008).

Falamos de um mecanismo que opera em dinâmicas múltiplas; que permite ao artista e ao espectador (ou às singularidade participantes em fluxo de heterogênese) organizarem seus enquadramentos independentemente de narrativas anteriores, ou mesmo da carga histórico-simbólica dos materiais envolvidos. O encontro de singularidades e seu reconhecimento (ou do sujeito com a diferença; ou, ainda, da identidade com a alteridade, ambos sujeitos em processo, nos termos de Féral), a realização de ações e a demonstração do processo de realização dessas ações já constitui uma rede de afetações suficiente para produzir estímulos de trabalho à pulsão de criação.

Entretanto, sabemos que o que está em jogo na tensão entre a teatralidade e a performatividade é um duelo de desejos que se provocam e delimitam

\footnotetext{
${ }^{8}$ Grifos meus.
} 
simultaneamente e em devir. Portanto, não é forçoso reconhecer que a potência (ou pulsão) de criação (ou ficção) também está na chave da performatividade. A pulsão de criação, quando emoldurada pela metafísica da teatralidade, representa a potência inata do homem de inserir o vivido em outras instâncias, outras vidas que podem ser "apreendidas" na forma de narrativa, e tal potência não é algo que se possa suprimir inteiramente. Essa pulsão, porém, é permanentemente atravessada por forças que provocam, desestabilizam os discursos ficcionais então formatados, refratam os desenhos miméticos confrontando novas alteridades (nos termos de Féral) ou outras singularidades, da mesma forma como o cotidiano foi o campo inicial de desligamento para instauração da teatralidade. Entramos no campo da performatividade, cujos movimentos são sempre de ultrapassamento (no sentido deleuziano) e, portanto, de reinvenção dos estratos.

Pensemos os mecanismos que envolvem a performatividade com ferramentas teóricas alinhadas a sua própria velocidade processual. Se nos encontros em que se instaura a teatralidade, Féral trata em termos de "encontros entre sujeitos em processo," cujo resultado é o trabalho criador de produção de desenhos ficcionais sob a forma de narrativas, nas dinâmicas da performatividade o campo de atualizações parece demandar um envolvimento dos corpos em outra zona de afetação:

Eu dizia que havia duas idéias (sic) principais no cerne da obra performativa. A segunda consiste no engajamento total do artista colocando em cena o desgaste que caracteriza suas ações (...) Não se trata necessariamente de uma intensidade energética do corpo no modelo grotowskiano, mas de um investimento de si mesmo pelo artista. Os textos evocam a vivacidade (liveness) dos performers, de uma presença fortemente afirmada que pode ir até uma situação de risco real, e implica em um gosto pelo risco (...) (FÉRAL, p. 200, 2008).

O engajamento total do artista, portanto, não remete apenas a um colocar-se diante do outro, e daí desenvolver uma série de relações; mas de deixar-se atravessar por forças, simbólicas ou materiais, visíveis ou invisíveis que se 
desencadeiam tão logo efetuado o reconhecimento da diferença; e que afetam dinamicamente a totalidade dos estratos que definem os participantes, os redelimitam e os recriam pela relação. Sem tais atravessamentos, sem essa redefinição dos limites entre o eu e o outro, sem as heterogêneses próprias de cada encontro, não podemos pensar na criação do espaço virtual em que as atualizações ficcionais, narrativas ou pré-narrativas possam existir.

Em nossa perspectiva, o campo da teatralidade e da performatividade, inicialmente pensado como metafísico, se insere no plano de criação das singularidades específicas da linguagem (para além das línguas). Tanto a pulsão de criação que deseja dar novos sentidos ao vivido por meio da construção de narrativas, quanto a sua outra face que força a auto-destruição das formas para, assim, reinventá-las, são potencialidades humanas que trabalham além das dicotomias do sujeito. Tratam precisamente de deslocamentos em que o sujeito busca o limite da dissolução, expondo-se mesmo ao risco de vida (como aponta a autora) nesse percurso; para de tal experiência se recriar e recriar "o outro" em novos estratos.

Teatralidade e performatividade, pois, formam o plano não-transcendental, posto que não é alheio ao trabalho dos estratos da matéria, em que se atualizam as linguagens performativas (sob a forma de múltiplos desenhos ficcionais) e virtualizam todas as suas possibilidades em devir. Não é possível, nos parece, pensar esse processo senão como um fluxo de afetação contínua em trabalho incessante. Quando Féral fala do momento de irrupção da ficção (referindo-se à teatralidade), ou da não-intencionalidade da ficção, (verificado na ação da performance), está recortando, para efeito de análise, um instante específico dentro de um processo de afetações que é criativo e paradoxal.

Uma ação performativa afeta a totalidade dos participantes, e seu desejo de fuga da representação original não é suficiente para bloquear o trabalho de efabulação do outro. Da mesma forma, como um desenho ficcional mimético pode destruir-se quando atravessado por outra força que the escape. Exatamente, porque 
o espaço de operação de tais fenômenos está em suspensão, é um entre (se ainda insistirmos na noção de sujeitos), ou um plano virtual, cujos preenchimentos movem-se com mais ou menos velocidade, pressionando ou esgarçando sentidos.

Em sua obra de referência $O$ que é o Virtual?, Pierre Lévy classifica as três virtualizações que, em suas palavras, "fizeram o humano": a linguagem, a técnica e o contrato. Fiquemos com a linguagem, em duas passagens de grande valia para nosso debate:

A linguagem, em primeiro lugar, virtualiza um "tempo real" que mantém aquilo que está vivo prisioneiro do aqui e agora. Com isso, ela inaugura o passado, o futuro e, no geral, o Tempo como um reino em si, uma extensão provida de sua própria consistência. $A$ partir da invenção da linguagem, nós humanos, passamos a habitar um espaço virtual, o fluxo temporal tomado como um todo, que o imediato presente atualiza apenas parcialmente, fugazmente. Nós existimos. O tempo humano não tem o modo de ser de um parâmetro ou de uma coisa (ele não é, justamente, 'real'), mas o de uma situação aberta. Nesse tempo assim concebido e vivido, a ação e o pensamento não consistem apenas em selecionar possíveis já determinados, mas em reelaborar constantemente uma configuração significante de objetivos e de coerções, em improvisar soluções, em reinterpretar, deste modo, uma atualidade passada que continua a nos comprometer ${ }^{9}$ (LÉVY, p. 71-73, 2007).

E, sobre o tempo das linguagens artísticas:

Os signos não evocam apenas "coisas ausentes", mas cena, intrigas, séries completas de acontecimentos ligados uns aos outros. Sem as línguas, não poderíamos nem colocar questões, nem contar histórias, duas belas maneiras de nos desligarmos do presente intensificando, ao mesmo tempo, nossa existência. Os seres humanos podem se desligar parcialmente da experiência corrente e recordar, evocar, imaginar, jogar, simular. Assim, eles decolam para outros lugares, outros momentos, outros mundos. Não devemos esses poderes apenas às línguas, como o francês, o inglês ou o wolof, mas igualmente às linguagens plásticas, visuais, musicais, matemáticas, etc. Quanto mais as linguagens se enriquecem e se estendem, maiores são as possibilidades de simular, imaginar e fazer imaginar um alhures, ou uma alteridade.

\footnotetext{
${ }^{9}$ Grifos meus.
} 
(...) As linguagens humanas virtualizam o tempo real, as coisas materiais, os acontecimentos atuais e as situações em curso. Da desintegração do presente absoluto, surgem, como as duas fases da mesma criação, o tempo e o fora-do-tempo, o anverso e o reverso da existência. Acrescentando ao mundo uma dimensão nova, o eterno, o divino, o ideal têm uma história. Eles crescem com a complexidade das linguagens. Questões, problemas, hipóteses abrem buracos no aqui e agora, desembocando, do outro lado do espelho, entre o tempo e a eternidade, na existência virtual ${ }^{10}$ (LÉVY, p. 72-73, 2007).

É no campo virtual da linguagem que a criação encontra o espaço privilegiado para recombinar o vivido e produzir novas sínteses como resposta. Se tanto teatralidade como performatividade nascem da irrupção de linhas de fuga do cotidiano (a primeira desejando e a segunda repudiando a produção de sentidos), elas participam do plano virtual da linguagem amplificando suas possibilidades. Da mesma forma, no caminho contrário: as novas linguagens são possíveis precisamente porque são processadas nesse campo virtual específico.

Conforme vimos acima, a noção de Tempo como extensão provida de consistência própria, fundada com o nascimento da(s) linguagem(ns) é um esforço de re-dimensão do ser-em-vida que não possui parâmetros externos, posto que às palavras de Lévy, não é real (é, portanto, uma situação aberta, diferentemente de uma abstração). Os fenômenos da teatralidade e da performatividade, nesse contexto, inauguram não somente um espaço outro, um espaço ficcional mais ou menos dramático, mais ou menos narrativo. Eles determinam um tempo particular mensurável apenas pela própria dinâmica interna do acontecimento-encontro, heterogênese de singularidades no plano virtual das linguagens artísticas.

O plano de composição da arte radicaliza a função criadora característica do plano das linguagens em geral. Toda produção de linguagem demanda a criação, e o Tempo talvez seja sua obra mais poderosa para estruturação do humano como

\footnotetext{
${ }^{10}$ Grifos meus.
} 
tal. Porém, o trabalho da efabulação, da criação de narrativas e sua desconstrução presentes nos encontros em que se instaura a teatralidade e a performatividade, e os desenhos ficcionais daí resultantes, não são esforços de outra natureza senão de realocar o ser em processo (nas palavras de Féral) num tempo-espaço distinto daquele identificado como cotidiano. $\mathrm{E}$ tal conjunto de atualizações não habita 0 mundo das fantasias, o negativo metafísico do real. Elas formam uma realidade tão consistente quanto o cotidiano.

Eis porque, voltamos à noção de envolvimento total do performer. Buscamos palavras para dar conta desses processos de re-territorialização das singularidades, específicos dos encontros artísticos, e do que sucede a partir de então. Teatralidade e performatividade são espaços que podem redimensionar o tempo, e, certamente, redefinem os limites globais dos participantes. A linguagem produzida é o rastro no tempo, a assinatura do processo num esforço fugaz de historicização.

Cada linguagem, cada desenho ficcional e cada ato de fuga da representação são frutos do fluxo da criação, seja ela uma pulsão inata ou adquirida. Seu espaço não está em lugar algum, mas pode estar em todas as partes. Nesse contexto, pensar distintamente teatralidade e performatividade parece mais uma questão de déficits de aceleração do que de ontologia e a condição de ambos torna-se menos um efeito casual e mais a ação, mais ou menos velada, mais ou menos consciente do desejo: um desejo tão grande de ser-em-vida, que a própria vida exige que a reinvente. 


\section{REFERÊNCIAS BIBLIOGRÁFICAS}

\section{Artigos}

FÉRAL, Josette. Performance and Theatricality: The Subject Demystified.

Modern Drama. New York, v. 25, n. 1, p. 170-181. mar. 1982.

. Theatricality: The Specifity of Theatrical Language. SubStance, Vol. 31, Edição $98 / 99$.

. Por uma poética da performatividade: o teatro performativo. Sala Preta, revista de Artes Cênicas, Edusp. n8, p. 191-210. 2008.

\section{Livros}

ALLIEZ, Éric. Deleuze Filosofia Virtual. São Paulo: editora 34, 1996.

BIRRINGER, Johannes. Performance on the edge. New York: Continuum, 1999.

CARLSON, Marvin. Performance a critical introduction. New York: Routledge, 2004.

DELEUZE, Gilles e GUATTARI, Felix. Mil Platôs Capitalismo e Esquizofrenia. vol 1.

São Paulo: editora 34, 1995.

. Mil Platôs Capitalismo e Esquizofrenia. vol. 2. São Paulo: editora 34, 1995.

. Mil Platôs Capitalismo e Esquizofrenia. vol 3. São Paulo: editora 34, 1996.

. Mil Platôs Capitalismo e Esquizofrenia. vol. 4. São Paulo: editora 34, 1997.

. O que é Filosofia?. São Paulo: editora 34, 1992.

FÉRAL, Josette. Teatro, Teoría y Práctica: más allá de las Fronteras. Galerna: Buenos Aires, 2004.

LÉVY, Pierrre. O que é o virtual?. São Paulo: editora 34, 1996. 